\title{
Life Histories and Vulnerability to Exploitation of Elasmobranchs: Inferences from Elasticity, Perturbation and Phylogenetic Analyses
}

\author{
Michael G. Frisk and Thomas J. Miller \\ University of Maryland Center for Environmental Sciences \\ Chesapeake Biological Laboratory, P. O. Box 38, Solomons, MD 20688 USA \\ Nicholas K. Dulvy \\ Centre for Environment, Fisheries and Aquaculture Science, Lowestoft Laboratory \\ Lowestoft NR33 OHT United Kingdom
}

Frisk, M. G., T. J. Miller, and N. K. Dulvy. 2005. Life Histories and Vulnerability to Exploitation of Elasmobranchs: Inferences from Elasticity, Perturbation and Phylogenetic Analyses. J. Northw. Atl. Fish. Sci., 35: 27-45. doi:10.2960/J.v35.m514

\begin{abstract}
We used life history traits to categorize vulnerability of elasmobranchs to exploitation. However, the utility of this approach required that the links between life histories and population dynamics be explored. We constructed standardized three-stage matrix models for 55 species of sharks and rays. Using these models we (1) conducted elasticity analyses to determine how the vital rates of mortality $(M)$ and fertility $(f)$ influence elasmobranch population growth rate $r,(2)$ determined the response of elasticity to changes in the levels of exploitation, (3) estimated sensitivity of elasticity to perturbation in vital rates, and (4) examined the taxonomic distribution of model inputs and species vital rates, such as size at maturity $\left(L_{\text {mat }}\right)$, and total length $\left(L_{\max }\right)$. We found positive relationships between the elasticity of $\lambda$ (population growth rate) to changes in juvenile and adult stages to longevity and age of maturity; however, the age of maturity and the elasticity of $\lambda$ to changes in the adult stage relationship appeared to be invariant. There was a negative relationship between both longevity and age of maturity and the elasticity of $\lambda$ to changes in inter-stage transitions of the models. Under varying fishing levels, estimates of elasticity were robust to changes in survival. Elasticity and perturbation analyses suggested that compensatory responses to exploitation in elasmobranchs were less likely to be expressed as changes in fertility than as changes in juvenile and adult mortality and stage durations (i.e. changes in age of maturity). Combining vital rates and elasticities, we found similar suites of life histories and demographics within groups at various taxonomic levels.
\end{abstract}

Key words: Elasmobranchs, elasticity, evolution, life history, management, matrix analysis, perturbation, sensitivity, viviparity

\section{Introduction}

Several species of elasmobranchs have been shown to be vulnerable to population declines and even local extinction (Casey and Myers, 1998; Stevens et al., 2000; Simpfendorfer, 2000; Dulvy et al., 2000; Frisk et al., 2001; 2002). The key parameter for determining the vulnerability of a species to population declines when exploited is the intrinsic rate of population increase, $r$. Species exhibiting a high $r$ are more resilient to exploitation and likely recover more rapidly once harvesting ceases than species with a low $r$. The degree of vulnerability of individual species has also been linked to life history traits, such that species exhibiting the combination of large maximum body size, slow growth, late maturation (at a large size), and long lifespan appear to be most vulnerable (Walker and Hislop, 1998; Dulvy et al., 2000;
Stevens et al., 2000; Frisk et al., 2001). Life histories are constrained by trade-offs; slow-growing species tend to be large bodied and mature later in life and have lower annual reproductive output (Charnov, 1993; Reynolds et al., 2001; Frisk et al., 2002; Roff, 2002). It should not be surprising then to find that species with 'slow' life histories also have low $r$ values (Fenchel 1974; Musick 1999; Denney et al., 2002). However, the link between life history and population dynamics and specifically the link to the population-level response of the additional mortality resulting from exploitation remains unclear.

Demography, the schedule of survival and reproduction of each age class or life stage in a population, links life history and population dynamics. Matrix models are used often to understand demography because they provide both a convenient method for integrating vital 
rates (survival and fertility) and extrinsic anthropogenic factors such as exploitation or pollution across age or stage classes, and a means to calculate parameters useful for understanding population dynamics, e.g. $\left(\lambda=e^{r}\right)$ (Walker and Hislop, 1998; Cortés, 1998; Heppell et al., 1999; Brewster-Geisz and Miller, 2000; Caswell, 2001; Cortés, 2002; Frisk et al., 2002; Mollet and Cailliet, 2002). However, estimates of the rate of population growth vary with population density. Consequently estimates of population growth rate that currently characterize expoited populations are unfortunately not necessarily representative of the performance of virgin populations (Jennings et al., 1998; Smith et al., 1998; Reynolds et al., 2001; Cortes, 2002).

Sensitivity analysis of such matrix models can be used to help identify which life history stages contribute most to variation in the population growth rate $(r)$. Two common forms of analyses are typically used: sensitivity and elasticity (Benton and Grant, 1999). Sensitivity measures the effect of an absolute change in a vital rate upon population growth rate, whereas elasticity measures the effect of a proportional change in a vital rate on population growth rate (Benton and Grant, 1999; Caswell, 2001). Both sensitivity and elasticity elucidate critical aspects of a species life history, provide insight for the focus of natural selection and indicate where management actions may be most successful. When using sensitivity or elasticity analyses, exact estimates of population growth rates are not needed to understand how management actions, that act via manipulation of vital rates, will generally influence population growth. However, the sensitivities and elasticities calculated only apply to the initial vital rates, used to define the projection matrix. To understand how elasticity changes as vital rates vary, the sensitivity of elasticity must be estimated (Caswell, 1996). Sensitivities of elasticity allow for analysis of the population-level consequences of dynamic changes in vital rates that result from perturbation of the vital rates.

The pattern and extent of responses to external factors exhibited by an individual species may be constrained by its phylogeny. Species that share a subset of traits derived from a common ancestor often exhibit similar suites of life histories even though they may live in very different habitats (Pagel and Harvey, 1988; Harvey and Pagel, 1991). Thus, phylogenetic influences on variations in life histories and demography must be considered. Elasmobranchs are divided between two contrasting superorders: Galea and Batoidea. The Galea are represented in our analysis by predatory, shallow-water species of requiem sharks (Carcharhinidae) and hound sharks (Triakidae). The Batoidea include both skates (Rajidae) and rays (Myli- obatidae). Here, we examine links between elasmobranch demography and life history, using comparative analysis of the outputs of a standardized stage-based matrix projection model parameterized for 55 elasmobranch species. Specifically we: (1) examine how vital rates (juvenile and adult survival and fertility elasticities) vary with life history traits (longevity, age of maturity and body size), (2) examine how elasticities respond to varying levels of exploitation, using four representative species, and (3) test whether suites of life histories and demographic traits are linked to phylogenetic relationships. We report results at the superorder, order and family levels. Our results are not intended to estimate limits to exploitation, but rather to explore how different species and phylogenetic groups of species are potentially influenced by exploitation. We hope to add to the discussion of where in the elasmobranch life cycle potential compensatory responses may occur under exploitative or environmental changes and how these may differ across species groupings. Our primary goal is to link elasmobranch phylogeny, life history, and conservation.

\section{Methods}

\section{The Data}

We extracted estimates of age of maturity $\left(T_{\text {mat }}\right)$, longevity $\left(T_{\max }\right)$, and fecundity $(F)$ from the literature (Table 1). All published data we obtained were included in our analyses. Adequate data were available for 55 species from 12 families, namely: Carcharhinidae (22 species), Rajidae (9), Triakidae (9), Alopiidae (3), Lamnidae (3), Sphyrnidae (2), Squalidae (2 stocks), Urolophidae (2), Dasyatidae (1), Odontaspididae (1), Scyliorhinidae (1), and Myliobatidae (1). Reported estimates of age of maturity $\left(T_{\text {mat }}\right)$, length of maturity $\left(L_{\text {mat }}\right)$, maximum length $\left(L_{\max }\right)$ and longevity $\left(T_{\max }\right)$ were usually point estimates. However, if a range was available, the mid-point was used. Reported estimates of fecundity were either the average egg production per year, as for many skates, or the mean number of neonates born per year based on the size and frequency of litters for live-bearing species. Natural mortality rates were estimated using Hoenig's (1983) method, an empirical approach that determines total mortality $(Z)$ using species' maximum age $\left(T_{\max }\right)$ as a predictor. Data used in our analyses and references are available at http://hjort.cbl.umces.edu/elasmo.htm.

\section{The Models}

Several species had sufficient estimates of vital rates to justify using age-based (Leslie) projection matrix models, but this was not true of all species. Accordingly, we chose to use stage-based models for all species considered 
FRISK et al.: Life Histories and Vulnerability to Exploitation

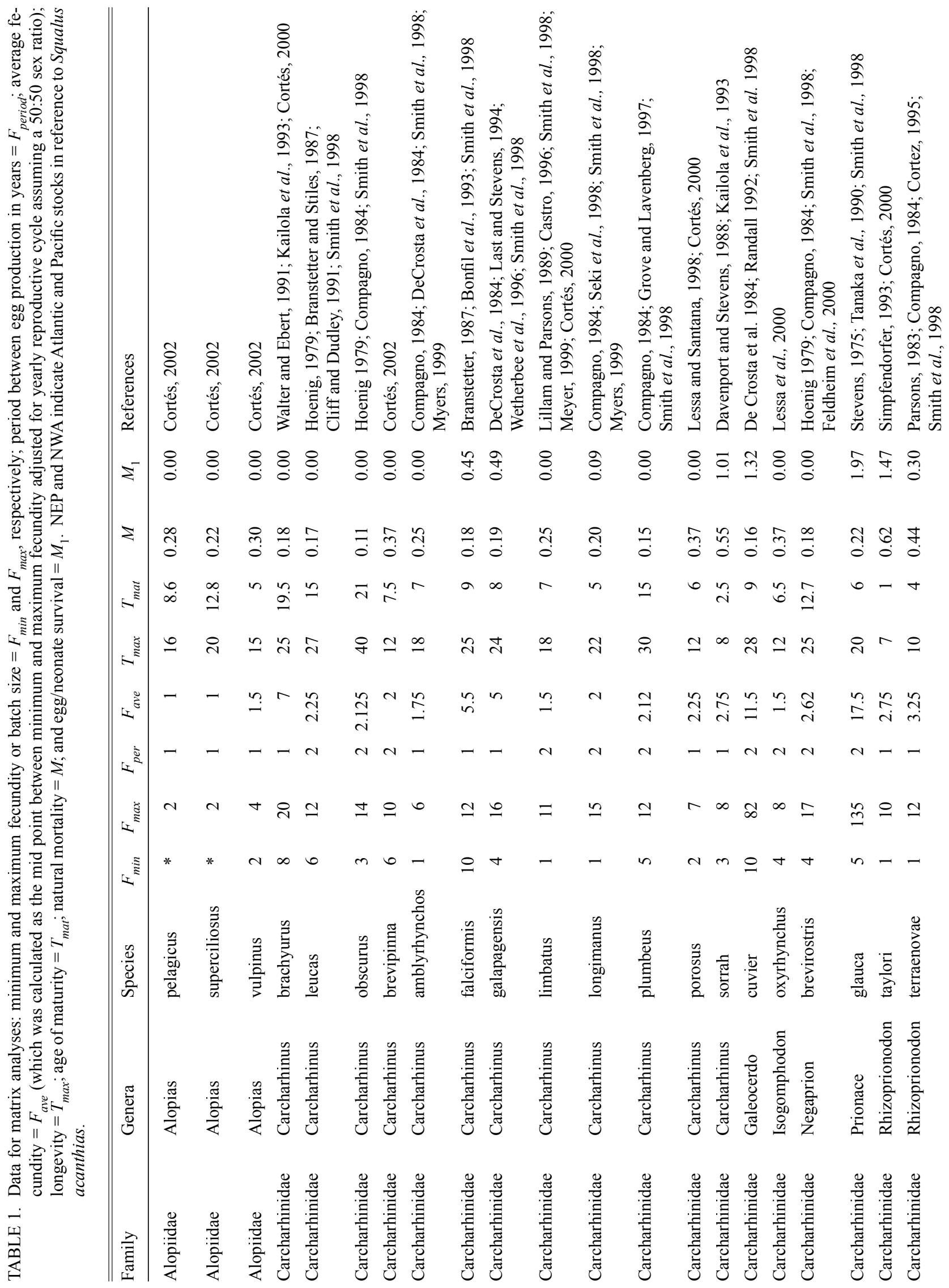




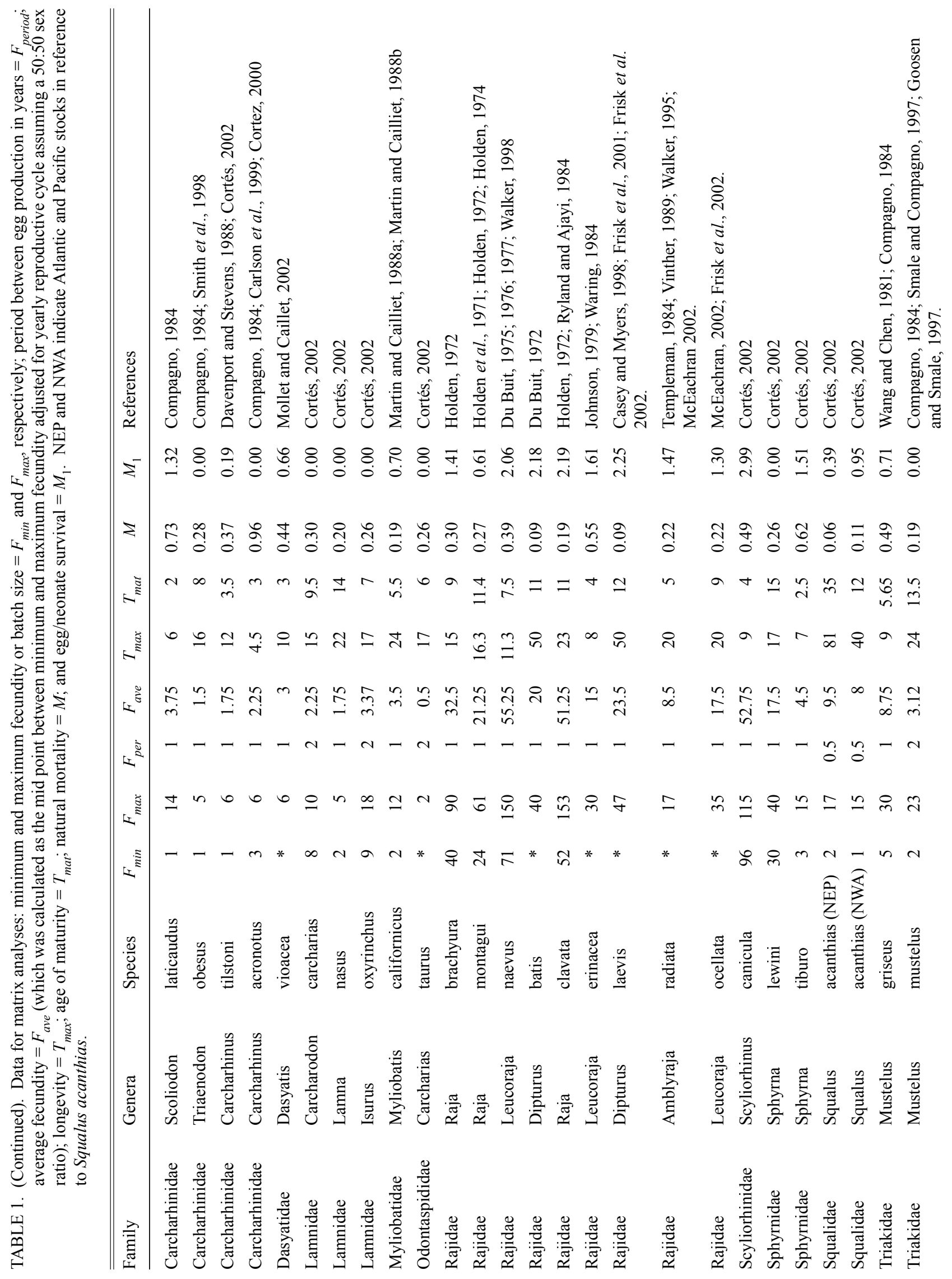


FRISK et al.: Life Histories and Vulnerability to Exploitation

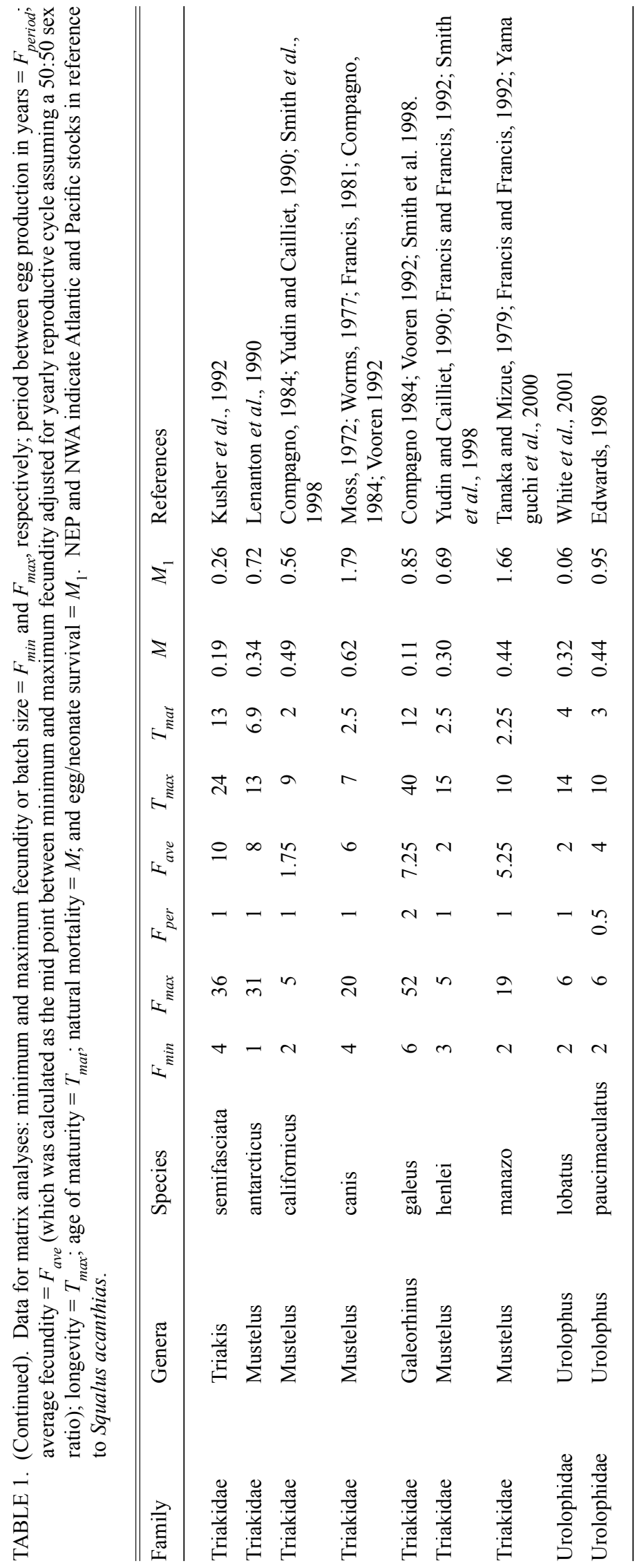


here to standardize methodologies among species. All models ran on an annual time step and involved three stages: an egg/neonate stage, a juvenile stage, and an adult stage. The egg or neonate stage lasted for a duration of one time step, while the juvenile and adult stages may have lasted several years. All models were programmed in MATHCAD (v11. Mathsoft Corp. Cambridge, MA).

In each model, individuals had three possible fates: they could survive and stay in the same stage, they could survive and grow into the next stage or they could die. The projection matrix took the form:

$$
A=\left[\begin{array}{ccc}
P_{1} & 0 & f \\
G_{1} & P_{2} & 0 \\
0 & G_{2} & P_{3}
\end{array}\right]
$$

Where $P$ was the probability of surviving and remaining in the same stage, $G$ was the probability of surviving and growing to the next stage and $f$ was fertility.

We assumed a post-breeding census for all species; thus, fecundity had to be weighted by the probability of adult survival (Caswell, 2001). Fertilities were calculated with the following function:

$$
f=P \cdot F
$$

where $F$ was annual fecundity.

$G$ and $P$ values were calculated using estimates of the probability that an individual survived $(\sigma)$ and the probability that an individual grew to the next stage $\left(\gamma_{i}\right)$ (Caswell, 2001). To determine the $P^{\prime}$ 's and $G$ 's to be used in the models, we assumed individuals within a stage have the same probability of survival, regardless of age. Following Caswell (2001), we iterated values of $\lambda_{\text {int }}$ in the equation:

$$
\gamma_{i}=\frac{\left(\frac{\sigma_{i}}{\lambda_{\text {int }}}\right)^{T_{i}}-\left(\frac{\sigma_{i}}{\lambda_{\text {int }}}\right)^{T_{i}-1}}{\left(\frac{\sigma_{i}}{\lambda_{\text {int }}}\right)^{T_{i}}-1}
$$

until $\lambda_{\text {int }}$ equaled the value for population growth rate $(\lambda)$ in the eigen analysis of the projection matrix. The resulting value of $\gamma_{i}$ was used to estimate appropriate values of $P_{i}$ and $G_{i}$.

Egg/neonate mortality was calculated by assuming that every female must, on average, have one female offspring survive to ensure population persistence. This condition was empirically estimated by calculating the level of first year mortaility $\left(M_{1}\right)$ necessary to sustain a positive growth rate given values of lifetime fecundity and mortality rates (Fogarty et al., 1987). This was calculated by satisfying the constraint that:

$$
1=\sum_{i=1}^{t_{\max }} F \prod_{j=1}^{i=1} \exp ^{-M_{j}}
$$

where $M$ was a vector of stage-specific mortalities and all other inputs were as defined above. In several species, the vital rates of fecundity, age of maturity, and longevity did not allow for any mortality in the egg/neonate stage. This may have resulted from low estimates of longevity or fecundity. In these cases we used a value of $M_{1}=0.0$. Our approach to estimating $M_{1}$ yielded estimates of population growth rate $(\lambda)$ that were correlated with estimates of neonate/egg stage mortality. However, as we were interested in the relationship between vital rates and their influence on growth rate and not estimates of population growth per $s e$, this covariation is not a critical concern.

Population growth rate $(\lambda)$ was determined from the dominant eigen value of matrix $\mathbf{A}$ (eq. 1). The intrinsic rate of population increase was calculated as $r=\ln (\lambda)$.

\section{Elasticity analyses}

Elasticity was calculated as:

$$
e_{i, j}=\left(\frac{a_{i, j}}{\lambda}\right)\left(\frac{\partial \lambda}{\partial \alpha_{i, j}}\right)
$$

where $a_{i, j}$ was the element in the $i^{\text {th }}$ row and $j^{\text {th }}$ column of the projection matrix and $\lambda$ was the population growth rate.

We developed regressions and multivariate analyses with model inputs, $\left(T_{\max }, T_{\text {mat }}, L_{\max }, L_{\text {mat }}\right)$, and elasticity values to elucidate underlying associations within the data to identify key aspects of the species life histories and phylogenic associations.

\section{Sensitivity of elasticity}

Sensitivity of elasticity determines the magnitude and direction of the effect of changes in individual transition elements in A on elasticity $\left(e_{i, j}\right)$. Sensitivity of the elasticity for $a_{i, j}$ is a measure of the rate of change of elasticity to changes in underlying matrix transitions. Sensitivities of $e_{i, j}$ provide an understanding of how life histories have shaped elasticity patterns (Caswell, 1996). For example, a positive sensitivity of the elasticity $\left(e_{3,3}\right)$ with respect to $a_{3,3}$ (adult survival) would indicate that increasing the probability of remaining in the adult stage would increase the elasticity of the adult stage, whereas increasing the probability of death (i.e., decreasing $a_{3,3}$ ) would have a 
negative effect on the elasticity of the adult stage $\left(e_{3,3}\right)$. If values of sensitivity of elasticities with respect to $a_{i, j}$ were negative, then reducing $a_{i, j}$ would increase $e_{i, j}$ and vice versa.

The sensitivity was calculated by taking the second derivative of $e_{i, j}$ with respect to the element $\left(a_{i, j}\right)$ in the elasticity matrix which had the greatest contribution to growth rate (Caswell, 1996; 2001), so that:

$$
\frac{\partial e_{i, j}}{\partial a_{k, l}}=\frac{a_{i, j}}{\lambda} \frac{\partial^{2} \lambda}{\partial a_{i, j} \partial a_{k, l}}-\frac{a_{i, j}}{\lambda^{2}} \frac{\partial \lambda}{\partial a_{i, j}} \frac{\partial \lambda}{\partial a_{k, l}}+\frac{\delta_{i, k} \delta_{j, l}}{\lambda} \frac{\partial \lambda}{\partial a_{i, j}}
$$

where $\delta_{i, k} \delta_{j, l}$ are Kronecker delta functions.

\section{Response to exploitation}

Exploitation can change average vital rates over the short-term as a result of gear selectivity favoring particular age classes or life stages and possibly over the long-term if fishing is applied at a constant level. To understand the dynamics of elasticity for varying fishing levels, we ran models in which the fishing mortality rate ranged from 0-3.0 for juveniles and adults. Here we selected little skate, Leucoraja erinacea, common skate, Dipturus batis, dusky shark, Carcharhinus obscurus, and Atlantic sharpnose shark, Rhizoprionodon terraenovae, to be representative of the range of elasmobranch life histories.

\section{Phylogenetic analysis}

We used multidimensional scaling (MDS) and analysis of similarities (ANOSIM) to test for differences in suites of demographic and life history traits among taxonomic groupings. ANOSIM is a non-parametric permutation test, analogous to multivariate analysis of variance, that computes a test statistic (Global $R$ ) reflecting difference between factors (superorder, order, family), contrasted among species within each factor (Clarke and Warwick, 1994). The test was implemented using PRIMER v5 (Clarke and Gorely, 2001). Both analyses were based on a matrix of Bray-Curtis similarities of fourth root transformed and standardized data. In order to maximize the taxonomic breadth of species included in this analysis, we used the following traits: annual fecundity, $T_{\operatorname{mat}}, T_{\max }, L_{\max }$, juvenile elasticity, adult elasticity and the interstage elasticity.

\section{Results}

\section{Variation in elasticity with life history traits}

Positive relationships were found between longevity $\left(T_{\max }\right)$ and the elasticity of $\lambda$ to changes in the juvenile and adult stages (survivals) for all elasmobranchs combined (Figs. 1 and 2). A significant relationship was found between age of maturity $\left(T_{\text {mat }}\right)$ and the elasticity of $\lambda$ to changes in juvenile survival (Fig. 3). The relationship between elasticity of $\lambda$ to changes in adult survival and age of maturity was not significant (Fig. 4). Longer-lived species and later-maturing species tend to have higher elasticities of juvenile and adult survival, although the rate of increase in elasticity decreases as longevity increases beyond 25 years (Figs. 3 and 4). These associations suggest that population growth rates $(\lambda)$ of short-lived, early-maturing elasmobranch species are less sensitive to changes in survival during juvenile and adult stages than longer-lived, later-maturing species.

Due to the structure of the matrices used, the estimated elasticities of $\lambda$ to changes in the inter-stage transitions, including fertility, were equal. The elasticity of $\lambda$ to changes in inter-stage transitions was negatively related to both longevity and age of maturity (Figs. 5 and 6). These relationships indicate that longer-lived species have lower elasticity of $\lambda$ to changes in the inter-stage transitions while short-lived and early maturing species have higher elasticity of $\lambda$ values for changes in inter-stage transitions. Taken all together, these relationships (Figs. 1-6) indicate a trade-off between survival and reproduction. Long-lived species may be investing more energy for survival in the juvenile and adult stages, while in short-lived species there appears to be selection pressure to advance rapidly through the stages and reproduce (Table 2).

\section{Sensitivity of elasticity}

In 25 of 34 species of Carcharhinidae, elasticity of $\lambda$ to changes in the adult stage contributed most to overall elasticity of population growth rates, while 8 showed larger contributions for the juvenile stage, and 1 for the fertility and transition stages. Of the 7 (Triakidae) species, 3 showed the greatest elasticity of $\lambda$ to changes in the adult stage and 4 for the juvenile stage. Of the 9 Rajidae species, 6 showed the greatest elasticity of $\lambda$ to changes in the adult stage and 3 for the juvenile stage. In total for species in the superorder Galea, 28 had the greatest elasticity of $\lambda$ to changes in matrix elements for the adult stage and 12 for the juvenile stage and 1 for inter-stage transitions. For the species in the superorder Batoidea, 12 had the greatest elasticity of $\lambda$ to changes in matrix elements for the adult stage and 3 for the juvenile stage.

Sensitivity of elasticity was calculated for the adult stage (stage with the greatest elasticity) of species from the superorder Galea. Figs. 7 and 8 show the sensitivity of elasticity values on a percent scale. Increases in survival of the adult stage would have the greatest positive effect of $e_{3,3}$ for Galea species (Fig. 7). Increases in the probability of transition from juvenile to the adult stage 


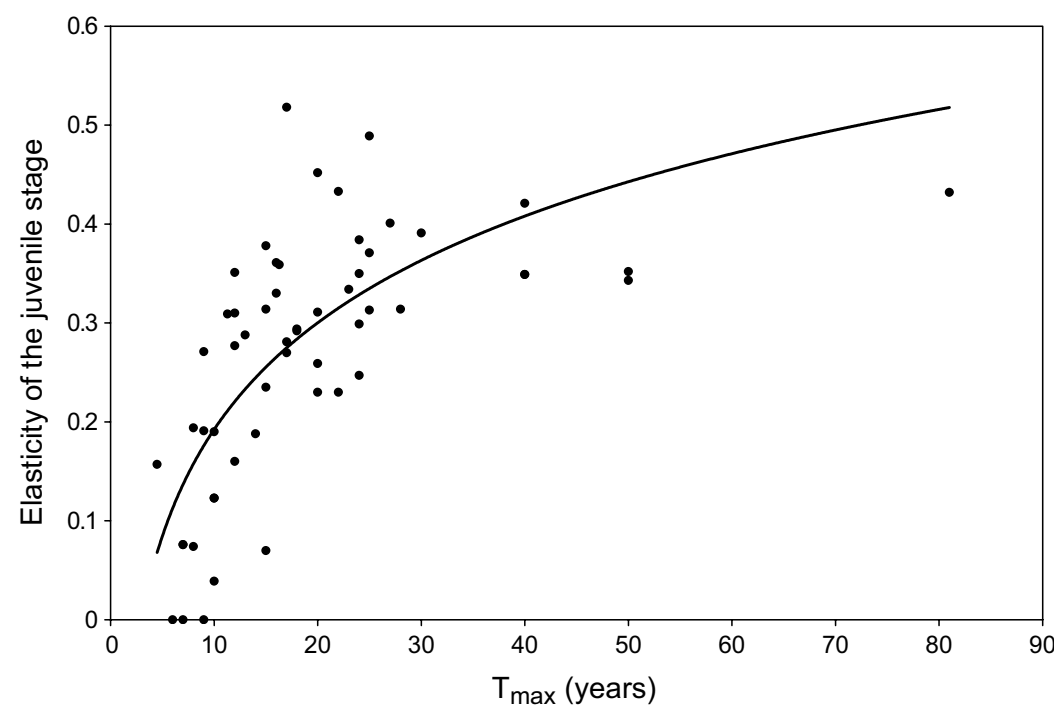

Fig. 1. The relationship between elasticity of $\lambda$ to changes in the juvenile stage and longevity $\left(T_{\max }\right)$. The least-squares relationship is given by e(juvenile) $=0.16 \bullet \operatorname{Ln}\left(T_{\max }\right)-0.17\left(n=56, r^{2}=0.51, P=0.00\right)$.

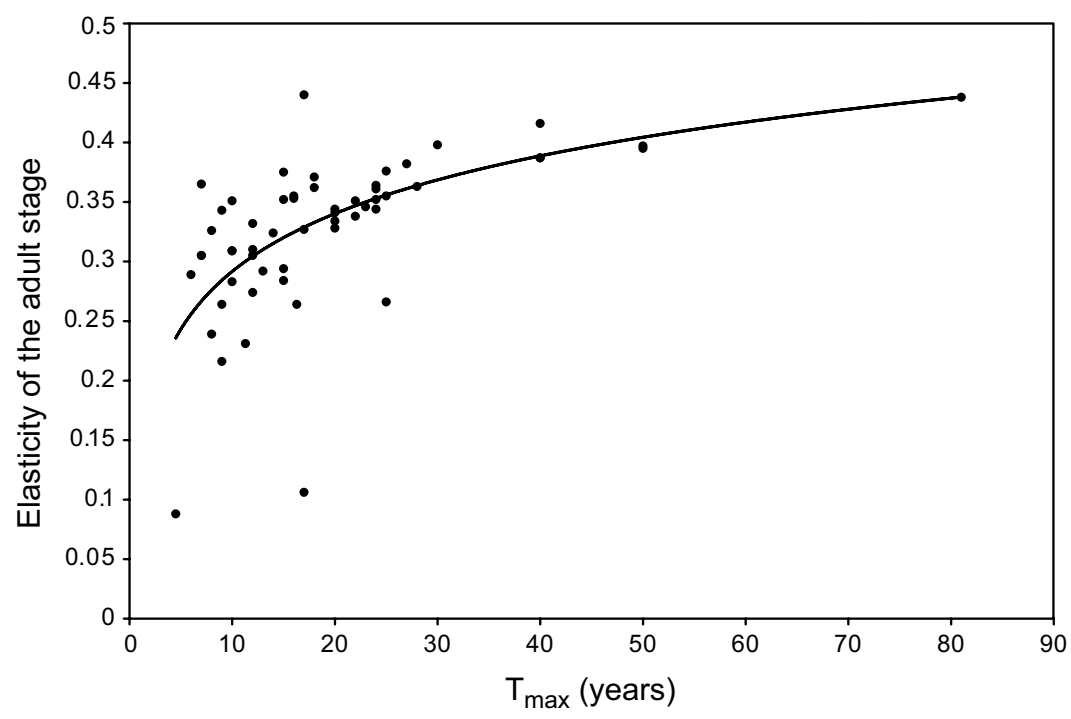

Fig. 2. The relationship between elasticity of $\lambda$ to changes in the adult stage and longevity $\left(T_{\max }\right)$. The least-squares relationship is given by $\mathrm{e}($ adult $)=$ $0.07 \bullet \operatorname{Ln}\left(T_{\max }\right)+0.13\left(n=56, r^{2}=0.38, P=0.00\right)$.

or juvenile survival would have large negative effects of $e_{3,3}$. In some cases, increases in the probability of transition to the juvenile stage had large negative effects on $e_{3,3}$, but importantly, changes to fertility would have little effect.

Patterns in the sensitivities of $e_{3,3}$ to changes in transition elements $a_{i, j}$ for species from the superorder Batoidea are similar to those found for Galea, with increases in the adult stage having large positive impacts and changes in the juvenile stage and the transitional stages and fertility element having negative effects (Fig. 8). For Batoidea and Galea species, the sensitivity of elasticity of species for the juvenile stage was positive, indicating that increased survival would have a positive effect on $e_{2,2}$ (Fig. 9). Changes in the transition to adulthood would have large negative effects on $e_{2,2}$. Smaller negative effects would 
FRISK et al.: Life Histories and Vulnerability to Exploitation

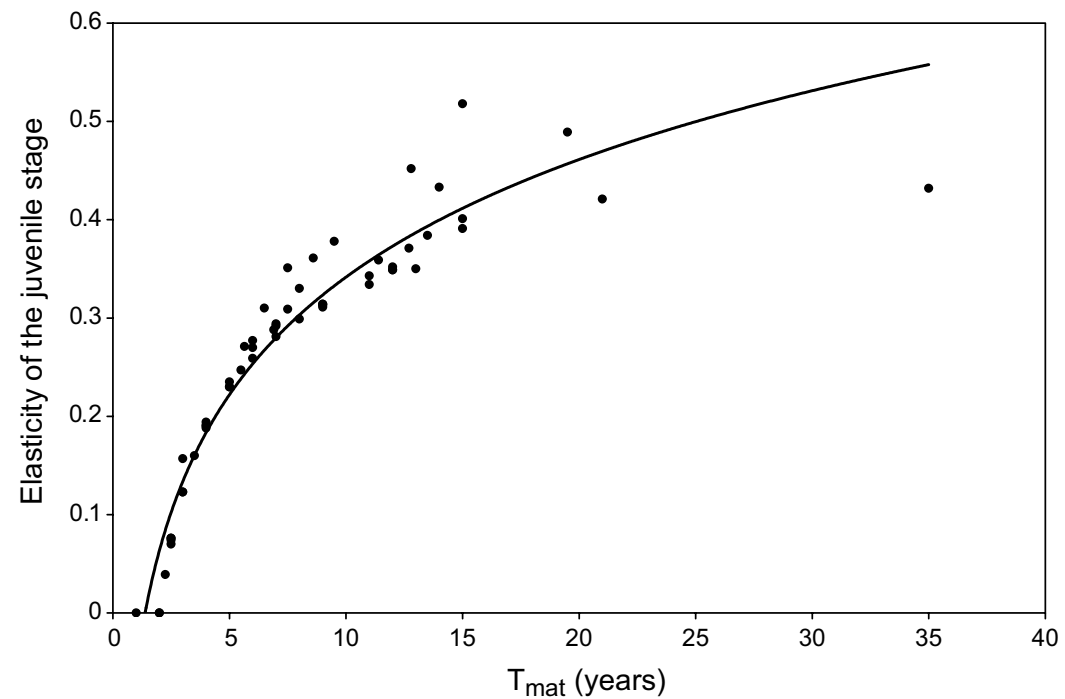

Fig. 3. The relationship between elasticity of $\lambda$ to changes in the juvenile stage and age of maturity $\left(T_{\text {mat }}\right)$. The least-squares relationship is given by e(juvenile) $=0.17 \bullet \operatorname{Ln}\left(T_{\text {mat }}\right)-0.05\left(n=56, r^{2}=0.92, P=0.00\right)$.

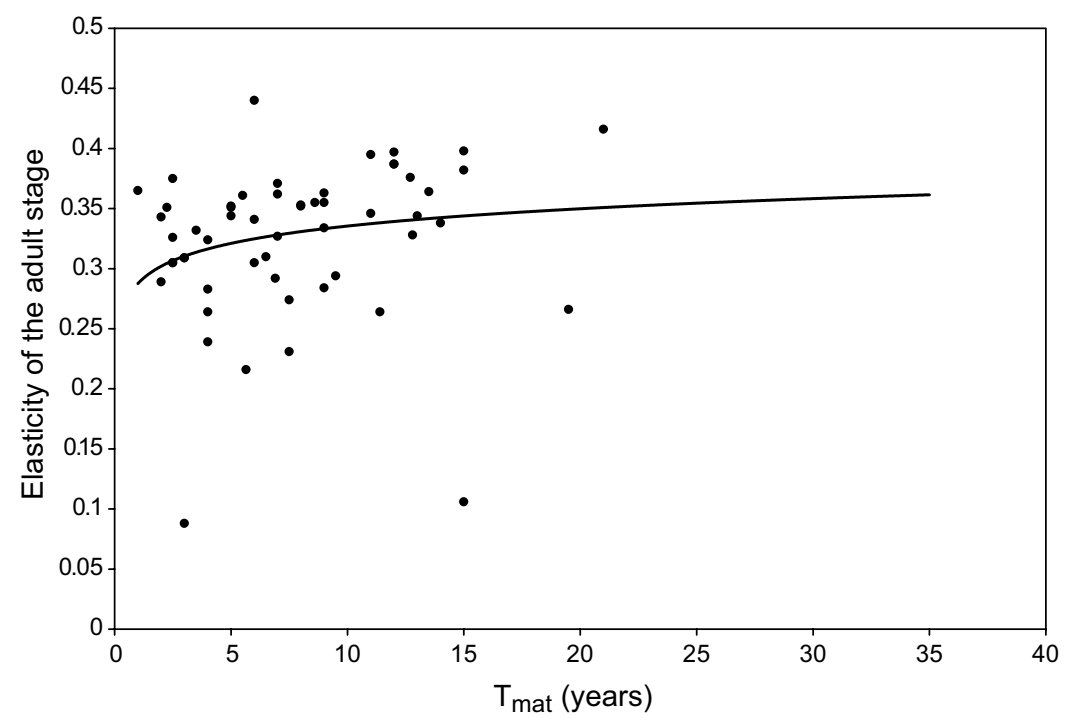

Fig. 4. The relationship between elasticity of $\lambda$ to changes in the adult stage and age of maturity $\left(T_{\text {mat }}\right)$. The least-squares relationship is given by e (adult $)=$ $0.02 \bullet \operatorname{Ln}\left(T_{\text {mat }}\right)+0.29\left(n=56, r^{2}=0.05, P=0.10\right)$.

result from perturbations of fertility, transition to juveniles and the adult stage survival.

\section{The response of elasticities to exploitation}

Estimates of elasticity varied little as (fishing) mortality rates were increased from low to moderate levels $(0-0.4)$. We illustrate the general pattern by showing details for little skate, common skate, dusky shark and the Atlantic Sharpnose shark (Table 3). When considering reasonable fishing mortality rates for little skate $(0-0.4)$, elasticity changed by $2 \%$ or less. Similar results can be seen for the short-lived, Atlantic sharpnose shark and the long-lived common skate and dusky shark. In probable management scenarios with fishing mortality in juvenile and adult stages ranging from $(0-0.4)$, elasticity stays relatively constant. 


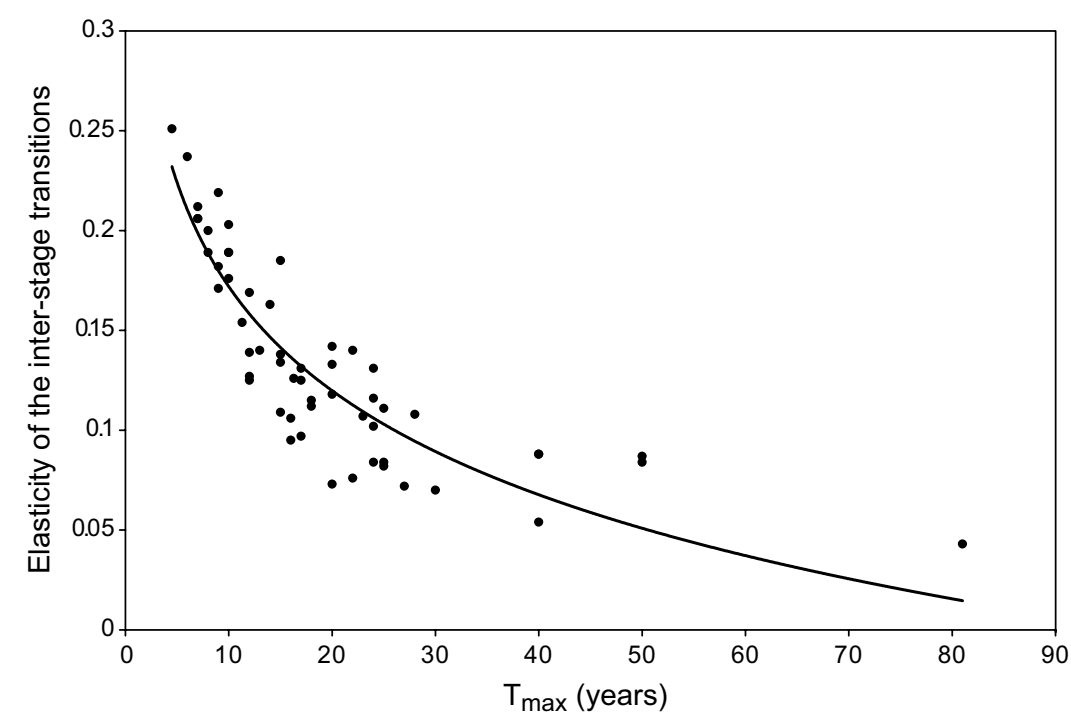

Fig. 5. The relationship between elasticity of fertility and the transition between stages and longevity $\left(T_{\max }\right)$. Note: in a three-stage model the elasticity of $\lambda$ to changes of both the transitional stages and fertility stage will be the same. The leastsquares relationship is given by e(inter-stage transitions $)=-0.07 \bullet \operatorname{Ln}\left(T_{\max }\right)+$ $0.34\left(n=56, r^{2}=0.79, P=0.00\right)$.

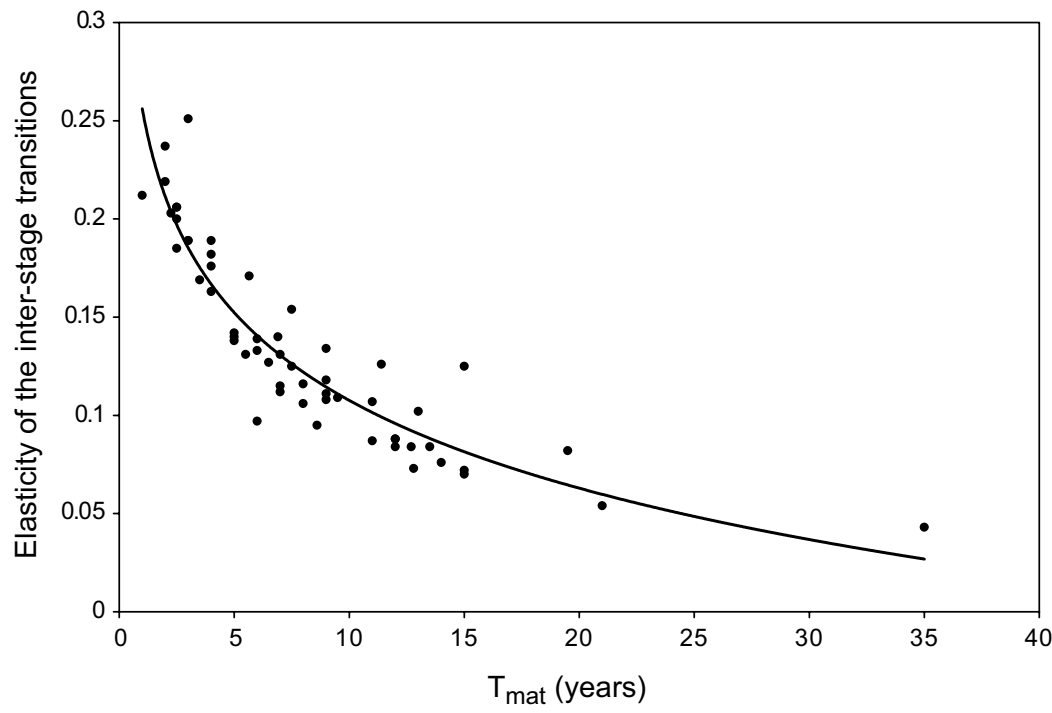

Fig. 6. The relationship between elasticity of $\lambda$ to changes in fertility and the transition between stages and age of maturity $\left(T_{\text {mat }}\right)$. The least-squares relationship is given by e (inter-stage transitions $)=-0.06 \bullet \operatorname{Ln}\left(T_{\text {mat }}\right)+0.26\left(n=56, r^{2}=\right.$ $0.86, P=0.00)$.

\section{Variation of life histories and elasticities with phylogeny}

A good MDS ordination was achieved with a low stress value (Fig. 10). The ordination clearly suggests a continuous gradation across the life histories-demography constraint space. High $L_{\max }$ values are associated with the right of the ordination, exemplified by Lamniformes such as the white shark, Carcharodon carcharias, and the thintail thresher shark, Alopias vulpinus (Fig. 11). High values of $T_{\max }$ are associated with the top of the ordination, exemplified by the spurdog, Squalus acanthias, the common skate, Dipturus batis, and the dusky shark, Carcharhinus 
TABLE 2. Relationships of vital rates of elasmobranchs species with elasticity of model parameters. Where (juv) = juvenile stage; $($ adult $)=$ adult stage and $(f, \operatorname{tr} 1, \operatorname{tr} 2)=$ fertility and the transition stages. $*$ indicates that the relationship was not significant.

\begin{tabular}{|c|c|c|c|c|c|}
\hline Species groups & Equation & $r^{2}$ & $\mathrm{~N}$ & $\mathrm{~F}$ & $\mathrm{p}$ \\
\hline Elasmobranchs & $\mathrm{e}(\mathrm{juv})=0.16 \cdot \operatorname{Ln}\left(T_{\max }\right)-0.17$ & 0.51 & 56 & 55.48 & 0.000 \\
\hline Elasmobranchs & $\mathrm{e}($ adult $)=0.07 \cdot \operatorname{Ln}\left(T_{\max }\right)+0.13$ & 0.38 & 56 & 33.49 & 0.000 \\
\hline Elasmobranchs & $\mathrm{e}(\mathrm{f}, \operatorname{tr} 1, \operatorname{tr} 2)=-0.07 \cdot \operatorname{Ln}\left(T_{\max }\right)+0.34$ & 0.79 & 56 & 204.34 & 0.000 \\
\hline Elasmobranchs & $\mathrm{e}(\mathrm{juv})=0.17 \cdot \operatorname{Ln}\left(T_{\text {mat }}\right)-0.05$ & 0.92 & 56 & 611.00 & 0.000 \\
\hline Elasmobranchs & $\mathrm{e}($ adult $)=0.02 \cdot \operatorname{Ln}\left(T_{m a t}\right)+0.29$ & 0.05 & 56 & 2.82 & $0.099 *$ \\
\hline Elasmobranchs & $\mathrm{e}(\mathrm{f}, \operatorname{tr} 1, \operatorname{tr} 2)=-0.06 \cdot \operatorname{Ln}\left(T_{\text {mat }}\right)+0.26$ & 0.86 & 56 & 323.56 & 0.000 \\
\hline Requiem sharks & $\mathrm{e}(\mathrm{juv})=0.19 \cdot \operatorname{Ln}\left(T_{\max }\right)-0.26$ & 0.57 & 34 & 43.34 & 0.000 \\
\hline Requiem sharks & $\mathrm{e}($ adult $)=0.07 \cdot \operatorname{Ln}\left(T_{\max }\right)+0.13$ & 0.30 & 34 & 13.71 & 0.001 \\
\hline Requiem sharks & $\mathrm{e}(\mathrm{f}, \operatorname{tr} 1, \operatorname{tr} 2)=-0.09 \cdot \operatorname{Ln}\left(T_{\max }\right)+0.37$ & 0.86 & 34 & 196.89 & 0.000 \\
\hline Requiem sharks & $\mathrm{e}(\mathrm{juv})=0.18 \cdot \operatorname{Ln}\left(T_{m a t}\right)-0.07$ & 0.94 & 34 & 487.07 & 0.000 \\
\hline Requiem sharks & $\mathrm{e}($ adult $)=0.01 \cdot \operatorname{Ln}\left(T_{\text {mat }}\right)+0.30$ & 0.02 & 34 & 00.60 & $0.44 *$ \\
\hline Requiem sharks & $\mathrm{e}(\mathrm{f}, \operatorname{tr} 1, \operatorname{tr} 2)=-0.06 \cdot \operatorname{Ln}\left(T_{\text {mat }}\right)+0.26$ & 0.87 & 34 & 208.13 & 0.000 \\
\hline Houndsharks & $\mathrm{e}(\mathrm{juv})=0.39 \cdot \operatorname{Ln}\left(T_{\max }\right)-0.76$ & 0.45 & 7 & 4.03 & 0.101 \\
\hline Houndsharks & $\mathrm{e}($ adult $)=0.00 \cdot \operatorname{Ln}\left(T_{\max }\right)+0.34$ & 0.00 & 7 & 0.00 & $0.99 *$ \\
\hline Houndsharks & $\mathrm{e}(\mathrm{f}, \operatorname{tr} 1, \operatorname{tr} 2)=-0.13 \cdot \operatorname{Ln}\left(T_{\max }\right)+0.47$ & 0.57 & 7 & 6.59 & 0.050 \\
\hline Houndsharks & $\mathrm{e}(\mathrm{juv})=0.22 \cdot \operatorname{Ln}\left(T_{m a t}\right)-0.12$ & 0.96 & 7 & 135.84 & 0.000 \\
\hline Houndsharks & $\mathrm{e}($ adult $)=-0.06 \cdot \operatorname{Ln}\left(T_{m a t}\right)+0.47$ & 0.22 & 7 & 1.45 & $0.28 *$ \\
\hline Houndsharks & $\mathrm{e}(\mathrm{f}, \operatorname{tr} 1, \operatorname{tr} 2)=-0.05 \cdot \operatorname{Ln}\left(T_{\text {mat }}\right)+0.22$ & 0.68 & 7 & 10.46 & 0.023 \\
\hline Skates & $\mathrm{e}(\mathrm{juv})=0.06 \cdot \operatorname{Ln}\left(T_{\max }\right)+0.14$ & 0.37 & 9 & 4.10 & $0.08 *$ \\
\hline Skates & $\mathrm{e}($ adult $)=0.10 \cdot \operatorname{Ln}\left(T_{\max }\right)+0.02$ & 0.89 & 9 & 54.64 & 0.000 \\
\hline Skates & $\mathrm{e}(\mathrm{f}, \operatorname{tr} 1, \operatorname{tr} 2)=-0.05 \cdot \operatorname{Ln}\left(T_{\max }\right)+0.28$ & 0.89 & 9 & 57.18 & 0.000 \\
\hline Skates & $\mathrm{e}(\mathrm{juv})=0.14 \cdot \operatorname{Ln}\left(T_{m a t}\right)+0.00$ & 0.97 & 9 & 263.73 & 0.000 \\
\hline Skates & $\mathrm{e}($ adult $)=0.08 \cdot \operatorname{Ln}\left(T_{\text {mat }}\right)+0.15$ & 0.23 & 9 & 2.08 & $0.19^{*}$ \\
\hline Skates & $\mathrm{e}(\mathrm{f}, \operatorname{tr} 1, \operatorname{tr} 2)=-0.07 \cdot \operatorname{Ln}\left(T_{m a t}\right)+0.28$ & 0.74 & 9 & 20.34 & 0.003 \\
\hline
\end{tabular}

obscurus (Fig. 11). High annual fecundities are associated with egg-laying species in the lower left of the ordination such as the lesser spotted catshark, Scyliorhinus canicula, the thornback ray, Raja clavata, and the cuckoo ray, Leucoraja naevus (Fig. 11). The elasticity of $\lambda$ to changes in the juvenile stage does not appear to vary systematically over the ordination. Adult elasticity appeared to be highest in the middle, whereas the elasticity of $\lambda$ to changes in the interstage transitions was greatest in species at the bottom of this ordination (Fig. 11).

There were significant differences among superorders, orders and families in the ordination of their life histories and demography (Fig. 12A; superorder - Global $R=0.45, P<0.001$; order - Global $R=0.5, P<0.001$; family - Global $R=0.58, P<0.001)$. Both superorders appear distinct exhibiting only a small degree of overlap. The Lamniformes form a clear group on the right side of the order-level ordination (Fig. 12B). Some of the dorso-ventrally flattened skates and rays (Myliobatiformes and Rajiformes) overlap with Carcharhiniformes in this ordination (Fig. 12C). In the order-level analysis there were significant $(P<0.05)$ pairwise differences between Carcharhiniformes and both Lamniformes and Rajiformes. Lamniformes were significantly different from all other families. There was no significant pairwise difference between Carcharhiniformes and Myliobatiformes or between Rajiformes and Myliobatiformes. There was considerable overlap in the life histories and demography of families at the centre of the ordination particularly among the shark families Carcharhinidae, Sphyrnidae, and the live-bearing ray families Myliobatidae, Dasyatidae and Urolophidae. 


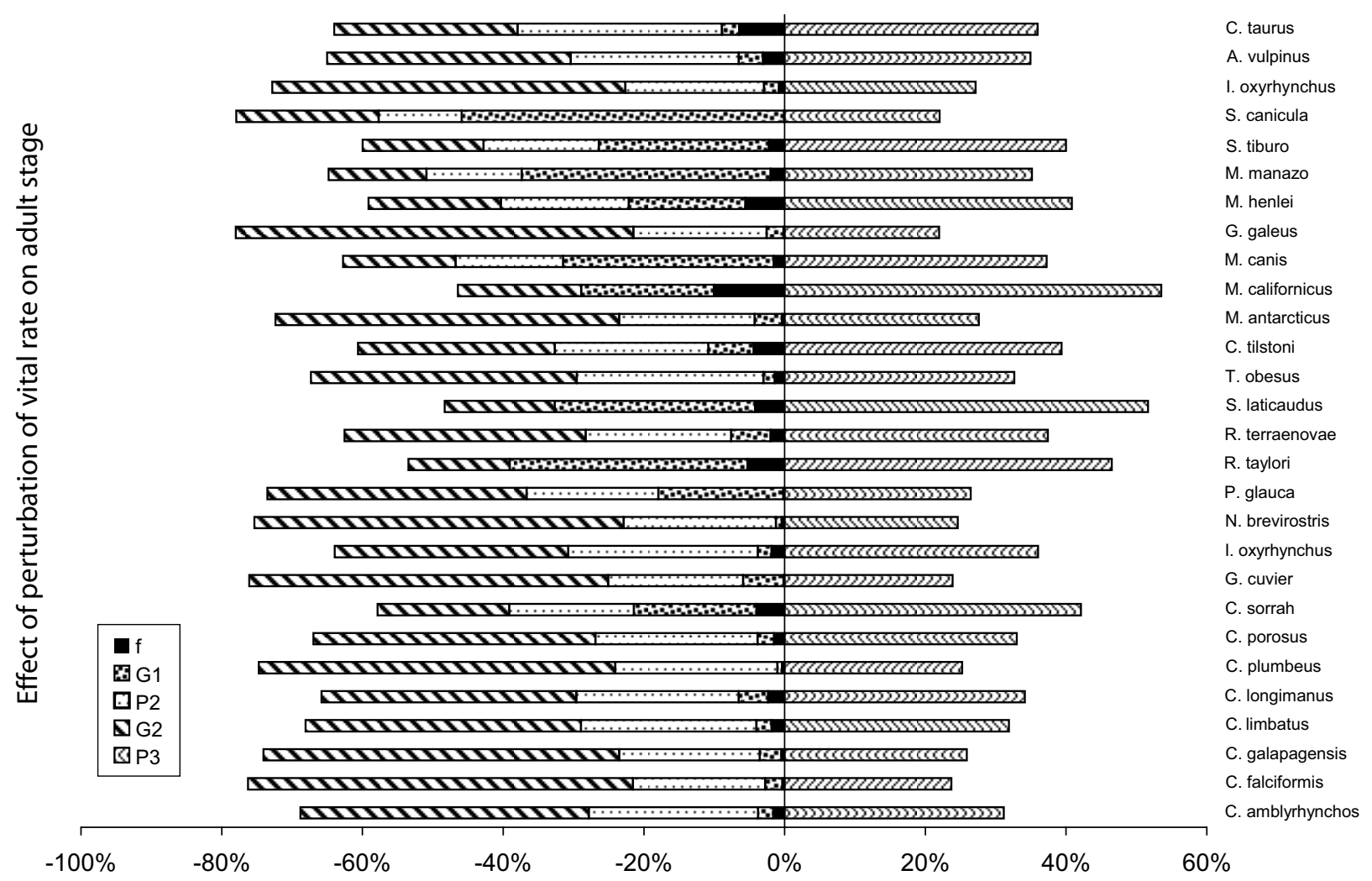

Fig. 7. The sensitivities of elasticity of the adult stage are shown for species in the superorder Galea for each stage of the matrix. The sensitivities to elasticity are shown as a percentage. Thus, the relative proportion (percentage) a stage has $\left(a_{i, j}\right)$, indicates the magnitude of the effect of changes of elements $\left(a_{i, j}\right)$ in $\mathbf{A}$, will have on the resulting elasticities $\left(e_{i, j}\right)$. Here the relative proportion (percentage) is of importance not the direction (negative or positive sign).

The families around the centre of the ordination included the egg-laying skates Rajidae and a catshark (Scyliorhinidae), the long-lived spurdog (Squalus acanthias, Squalidae), and the large pelagic predators of the mackerel (Lamnidae) and thresher sharks (Alopiidae).

\section{Discussion}

Insights into how elasmobranch population dynamics are regulated can be gained from the combination of elasticity, perturbation and phylogenetic analyses. Our analyses revealed three fundamental features of elasmobranch demography and population dynamics. Most fundamentally, we found evidence for a trade-off between survival and reproductive investment (elasticity analysis). Additionally, we observed that in the majority of species growth (survival) into adult stages appeared most important in regulating a species response to exploitation (sensitivity of elasticity). Finally, we found that life history and demographic patterns are phylogenetically constrained, such that the population dynamics and responses to exploitation of related species will be more similar than those of distantly related species (phylogenetic analysis). However, our results suggest considerable overlap of families and orders across the life history-demography range.

In our models, juvenile elasticity increased (or was invariant) with increasing age at maturity and maximum age. This is in contrast to Cortés (2002), who, using an age-based Leslie type model, found that adult elasticity tended to decline with generation time. However, the model presented here, which uses collapsed age classes as stages, and the age-structured model of Cortés (2002) do produce similar results when age-based elasticities are added together to form each stage. Both analyses provide evidence that the trends observed in elasticity patterns apply to sharks and to the additional species of skates and rays that were included in the present analysis.

Elasticity analysis provided insights into what aspects of a species' life history will play important roles in understanding population level changes in response to both short-term changes in harvest policies and to longer term evolutionary pressures (de Kroon et al. 2000). We showed evidence for a trade-off between survival and reproduc- 


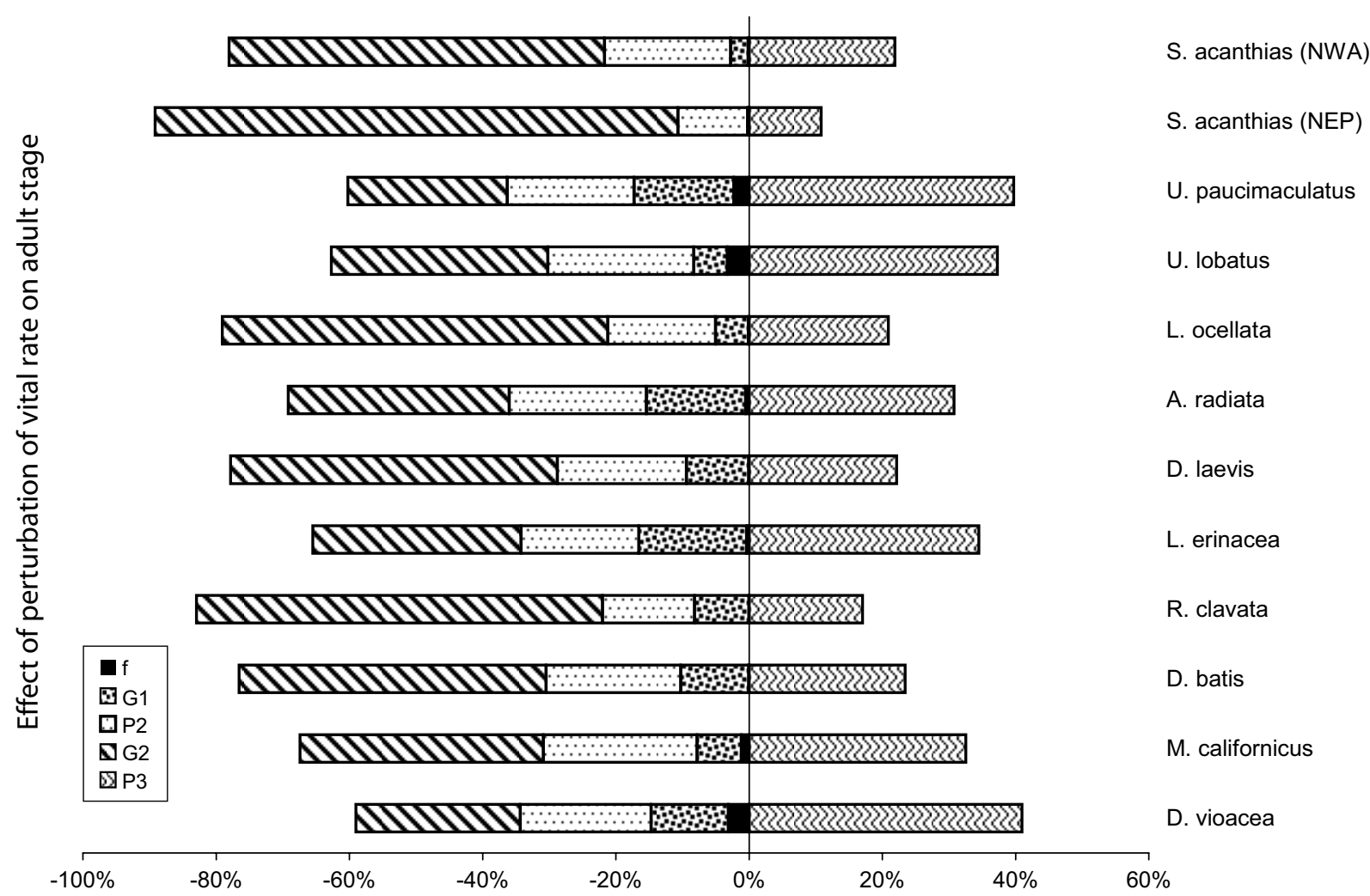

Fig. 8. The sensitivities of elasticity of the adult stage are shown for species in the superorder Batoidea for each stage of the matrix. The sensitivities to elasticity are shown as a percentage. Thus, the relative proportion (percentage) a stage has $\left(a_{i, j}\right)$, indicates the magnitude of the effect of changes of elements $\left(a_{i, j}\right)$ in $\mathbf{A}$, will have on the resulting elasticities $\left(e_{i, j}\right)$. Here the relative proportion (percentage) is of importance not the direction (negative or positive sign).

tive investment. Generally, short-lived species had higher elasticities of $\lambda$ to changes in inter-stage transitions (selection pressure on age of maturity and fertility), whereas long-lived species tended to have higher elasticities of $\lambda$ to changes in adult and juvenile survival. These are relative differences, and it should be noted that the elasticity of $\lambda$ to changes in inter-stage transitions is usually less than that of survival for short- and long-lived species. Our findings broaden the support of a continuum of life histories for elasmobranchs (Cortés, 2002). While this had previously been described in univariate terms (Smith et al., 2000; Cortés, 2000, 2002), we show that the pattern is clearly multivariate and may be described as a slow-fast life history-demography continuum. In particular, there is a high degree of overlap or convergence in the life histories and demography of morphologically and phylogenetically distinct taxa such as skates and rays.

The elasmobranchs studied here generally do not show high levels of variation in demographic vital rates, despite widely varying life history traits. However a reproductive mode does emerge as a life history trait that differs markedly among elasmobranchs. Live-bearing evolved 9-10 times from egg-laying ancestors and is found in 60\% of elasmobranch species (Wourms, 1977; Wourms and Lombardi, 1992; Dulvy and Reynolds, 1997). In addition, elasmobranchs exhibit a broad diversity in the extent of maternal provisioning of neonates, ranging from yolk-only to uterine cannibalism to complex placentation (Wourms, 1977; Wourms and Lombardi, 1992; Dulvy and Reynolds, 1997). The transition from egg-laying to livebearing possibly reflects a trade-off occurring when the benefits of increased offspring survival exceeds the cost of reduced fecundity (Goodwin et al., 2002). Live-bearing elasmobranchs are larger than their egg-laying relatives (Goodwin, 2002). There are significant differences between live-bearing and egg-laying species in their life history and demography (Global $R=0.688, P<0.0001$; Fig. 13). However, the differences in life history and demography between an ancestral egg-layer and the skates which derived egg-laying from a live-bearing ancestor (Dulvy and Reynolds, 1997) appear to be minimal. 


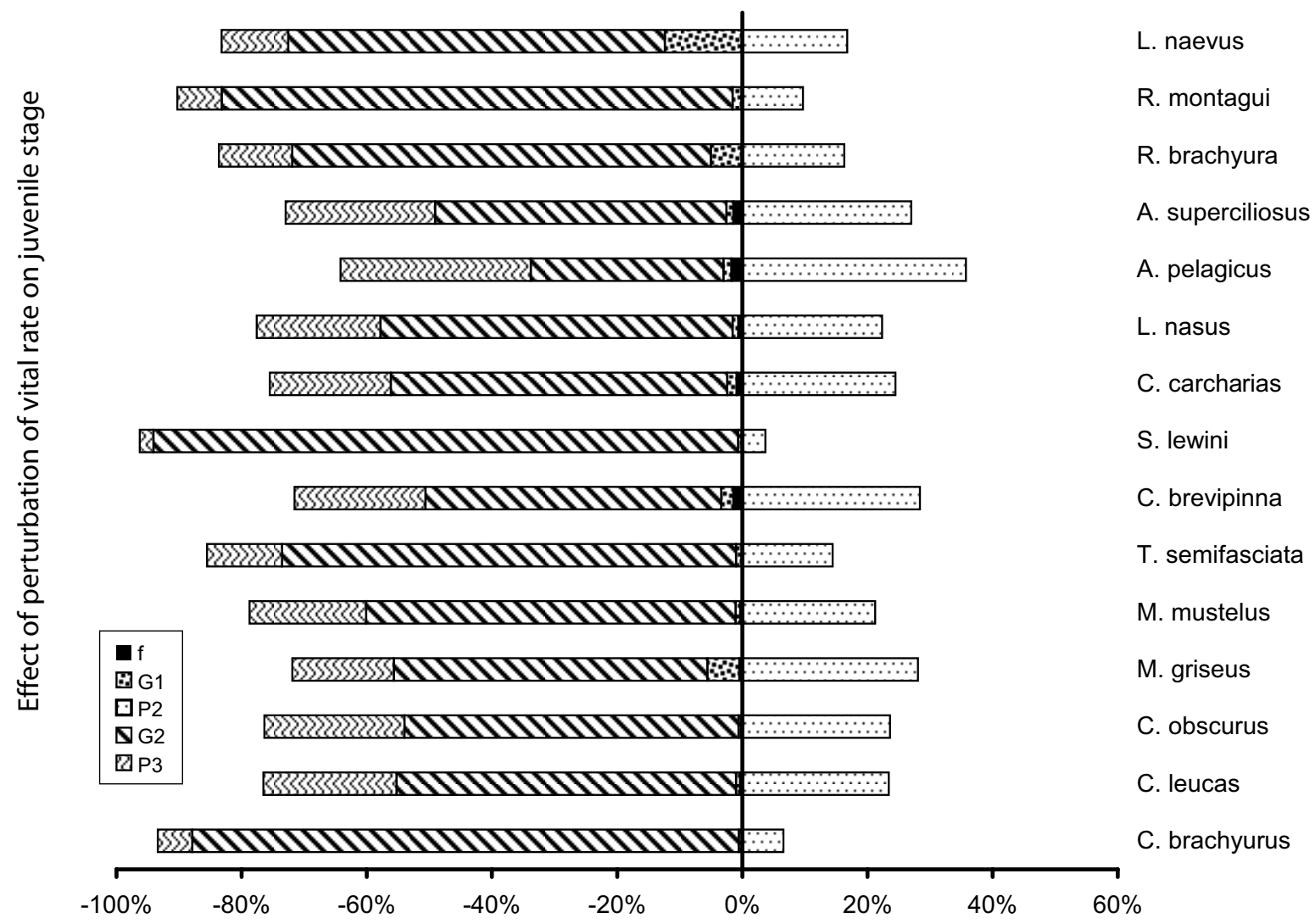

Fig. 9. The sensitivities of elasticity of the juvenile stage are shown for species of the superorders Batoidea and Galea for each stage of the matrix. The sensitivities to elasticity are shown as a percentage. Thus, the relative proportion (percentage) a stage has $\left(a_{i, j}\right)$, indicates the magnitude of the effect of changes of elements $\left(a_{i, j}\right)$ in $\mathbf{A}$, will have on the resulting elasticities $\left(e_{i, j}\right)$. Here the relative proportion (percentage) is of importance not the direction (negative or positive sign).

TABLE 3. The results of varying exploitation levels and elasticity patterns for shark and skate species, where (juv) $=$ juvenile stage; (adult) $=$ adult stage and $(f, \operatorname{tr} 1, \operatorname{tr} 2)=$ fertility and the transition stages.

\begin{tabular}{|c|c|c|c|c|c|c|c|c|c|c|c|c|}
\hline \multirow{2}{*}{$\begin{array}{l}\text { Fishing } \\
\text { mortality }\end{array}$} & \multicolumn{3}{|c|}{ Little skate } & \multicolumn{3}{|c|}{ Common skate } & \multicolumn{3}{|c|}{ Dusky shark } & \multicolumn{3}{|c|}{ Atlantic Sharpnose shark } \\
\hline & e(juv) & $\mathrm{E}$ (adult) & $\mathrm{e}(\mathrm{f}, \operatorname{tr} 1, \operatorname{tr} 2)$ & e(juv) & $\mathrm{e}$ (adult) & $\mathrm{e}(\mathrm{f}, \operatorname{tr} 1, \operatorname{tr} 2)$ & $\overline{\mathrm{e}(\mathrm{juv})}$ & e(adult) & $\mathrm{e}(\mathrm{f}, \operatorname{tr} 1, \operatorname{tr} 2)$ & $\overline{e(j u v)}$ & $\mathrm{e}$ (adult) & $\mathrm{e}(\mathrm{f}, \operatorname{tr} 1, \operatorname{tr} 2)$ \\
\hline 0 & 0.19 & 0.24 & 0.19 & 0.34 & 0.40 & 0.09 & 0.42 & 0.42 & 0.05 & 0.19 & 0.28 & 0.18 \\
\hline 0.2 & 0.19 & 0.23 & 0.19 & 0.34 & 0.39 & 0.09 & 0.42 & 0.42 & 0.05 & 0.19 & 0.27 & 0.18 \\
\hline 0.4 & 0.19 & 0.22 & 0.20 & 0.34 & 0.38 & 0.09 & 0.42 & 0.42 & 0.05 & 0.19 & 0.26 & 0.19 \\
\hline 0.6 & 0.18 & 0.22 & 0.20 & 0.34 & 0.38 & 0.09 & 0.41 & 0.41 & 0.06 & 0.18 & 0.25 & 0.19 \\
\hline 0.8 & 0.18 & 0.21 & 0.20 & 0.34 & 0.37 & 0.10 & 0.42 & 0.42 & 0.05 & 0.18 & 0.24 & 0.19 \\
\hline 1 & 0.17 & 0.20 & 0.21 & 0.34 & 0.37 & 0.10 & 0.42 & 0.41 & 0.06 & 0.18 & 0.23 & 0.20 \\
\hline 1.2 & 0.17 & 0.20 & 0.21 & 0.34 & 0.36 & 0.10 & 0.43 & 0.42 & 0.05 & 0.17 & 0.23 & 0.20 \\
\hline 1.4 & 0.17 & 0.19 & 0.21 & 0.34 & 0.36 & 0.10 & 0.43 & 0.43 & 0.05 & 0.17 & 0.22 & 0.20 \\
\hline 1.6 & 0.17 & 0.19 & 0.22 & 0.35 & 0.36 & 0.10 & 0.44 & 0.44 & 0.04 & 0.17 & 0.21 & 0.21 \\
\hline 1.8 & 0.16 & 0.18 & 0.22 & 0.35 & 0.36 & 0.10 & 0.45 & 0.45 & 0.03 & 0.17 & 0.20 & 0.21 \\
\hline 2 & 0.16 & 0.18 & 0.22 & 0.36 & 0.37 & 0.09 & 0.45 & 0.45 & 0.03 & 0.16 & 0.20 & 0.21 \\
\hline 2.2 & 0.16 & 0.17 & 0.22 & 0.37 & 0.37 & 0.09 & 0.46 & 0.46 & 0.02 & 0.16 & 0.19 & 0.22 \\
\hline 2.4 & 0.15 & 0.17 & 0.23 & 0.36 & 0.37 & 0.09 & 0.48 & 0.48 & 0.02 & 0.16 & 0.19 & 0.22 \\
\hline 2.6 & 0.15 & 0.16 & 0.23 & 0.35 & 0.35 & 0.10 & 0.48 & 0.48 & 0.01 & 0.16 & 0.18 & 0.22 \\
\hline 2.8 & 0.15 & 0.16 & 0.23 & 0.40 & 0.40 & 0.07 & 0.49 & 0.49 & 0.01 & 0.16 & 0.18 & 0.22 \\
\hline 3 & 0.15 & 0.16 & 0.23 & 0.41 & 0.41 & 0.06 & 0.50 & 0.50 & 0.00 & 0.15 & 0.17 & 0.23 \\
\hline
\end{tabular}




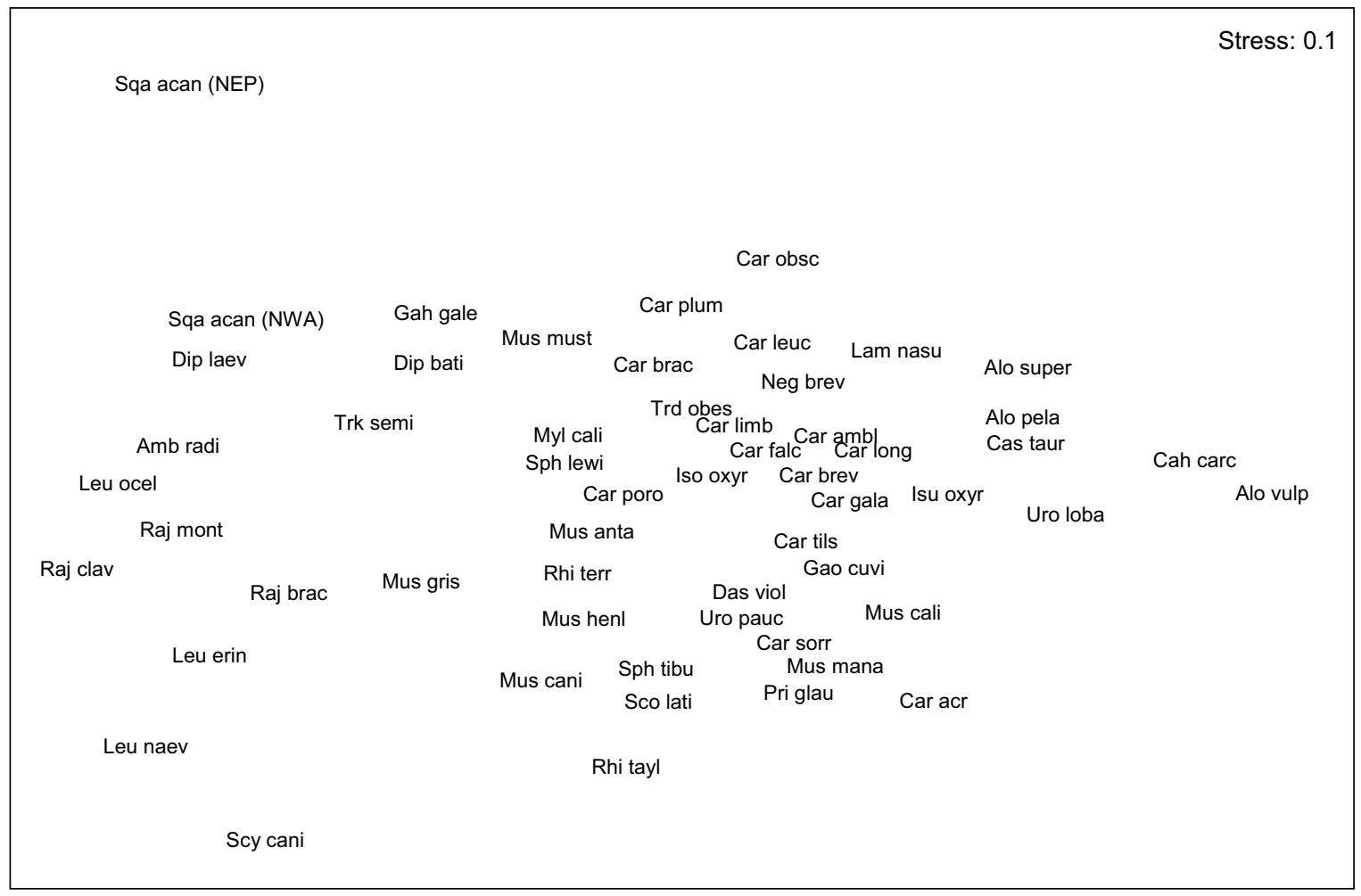

Fig. 10. MDS ordination of elasmobranch life histories and elasticities. This analysis was based on annual fertility, longevity, age at maturity, maximum length, juvenile and adult survival elasticities and the interstage transitional stage elasticity. Species in the centre of the ordination have been moved outward for clarity.
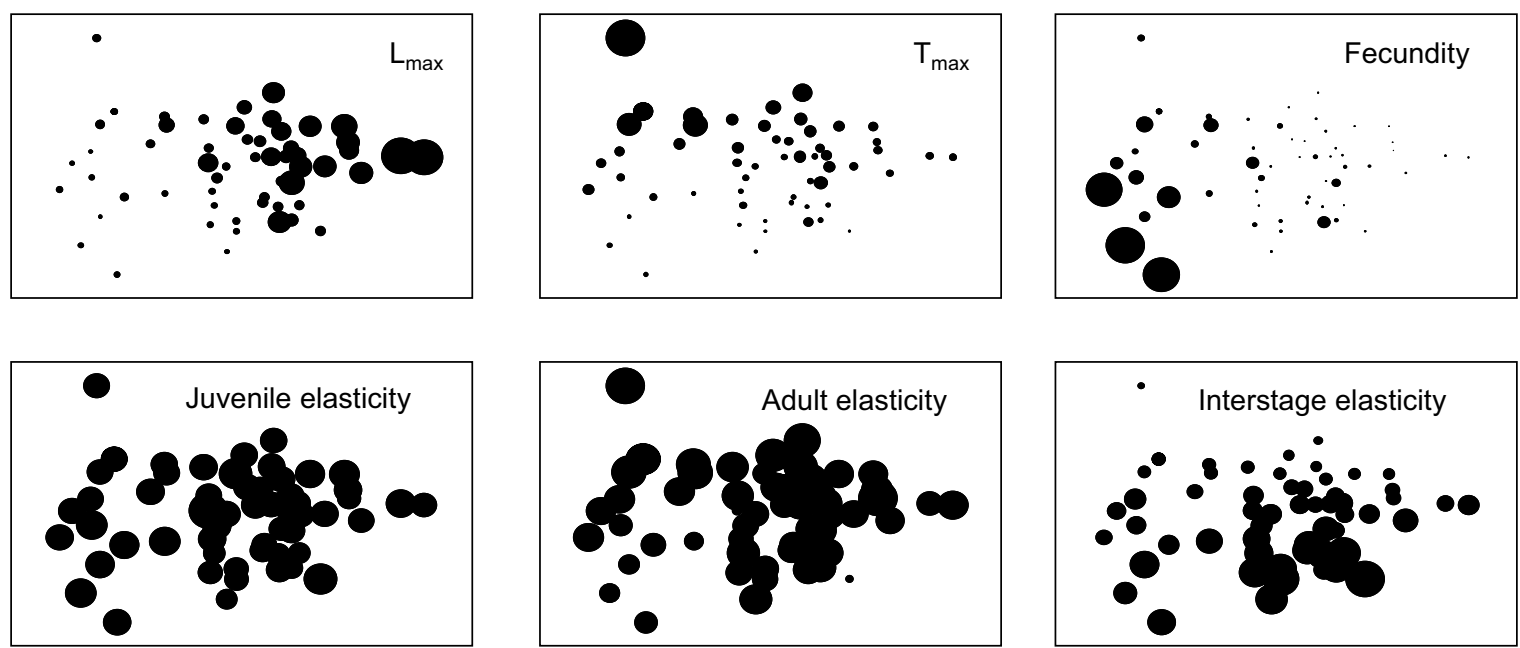

Fig. 11. MDS ordination of elasmobranch life histories and elasticities showing the relative magnitude of each trait.

There is considerable overlap in our ordination results between live-bearers which provide limited maternal investment, by provisioning the embryo only via the yolk of the ovum (leicithotrophy) and those which provide additional maternal input through placentation, uterine milk or oophagy (matrotrophy). Our finding of a survival-fertility trade-off and the relative importance of juvenile elasticities, particularly in larger-bodied, later-maturing species, would be consistent with the hypothesis that larger-bodied species might have evolved live-bearing to maximize offspring survival. The key question of what has driven the evolution toward large body sizes in elasmobranchs 


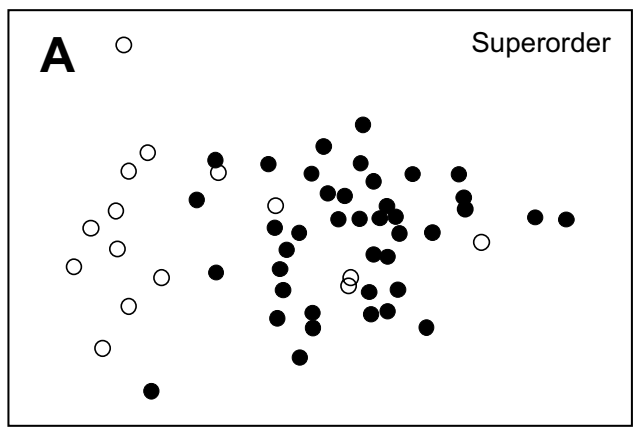

$\begin{array}{ll}\text { Galea } & \bullet \\ \text { Squalea } & \circ\end{array}$

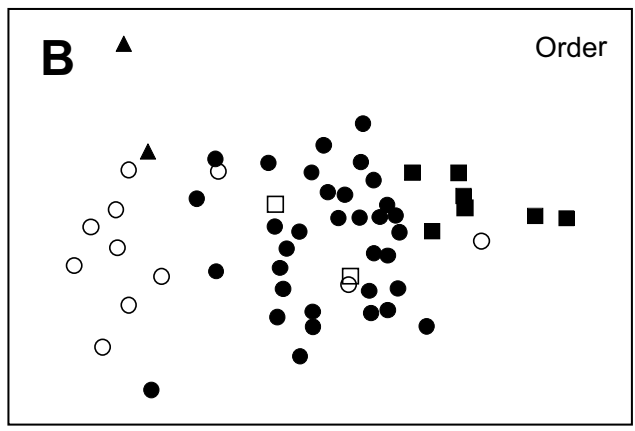

Carcharhiniformes

Lamniformes

Myliobatiformes

Rajiformes

Squaliformes

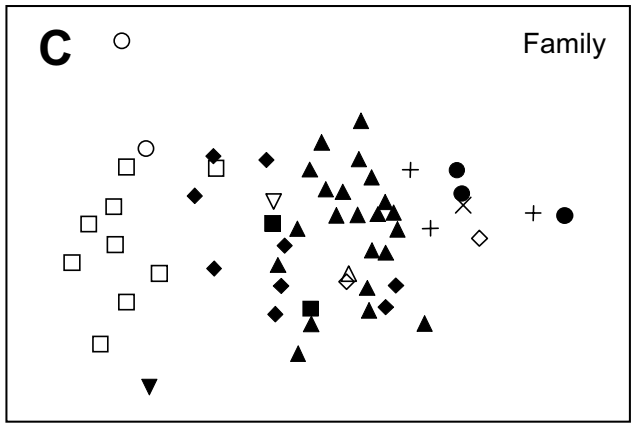

$\begin{array}{lc}\text { Carcharhinidae } & \boldsymbol{\Delta} \\ \text { Sphyrnidae } & \mathbf{\square} \\ \text { Alopiidae } & \bullet \\ \text { Odontaspidae } & \times \\ \text { Myliobatidae } & \nabla \\ \text { Urolophidae } & \diamond \\ \text { Scyliorhinidae } & \boldsymbol{\nabla} \\ \text { Triakidae } & \bullet \\ \text { Lamnidae } & + \\ \text { Dasyatidae } & \Delta \\ \text { Rajidae } & \square \\ \text { Squalidae } & \bigcirc\end{array}$

Fig. 12. MDS ordination of elasmobranch life histories and elasticities split by phylogenetic groupings, superorder (A), order (B) and family $(\mathbf{C})$.

remains largely open. However, a plausible hypothesis would be that body size constrains the maximum internal volume that offspring can occupy during gestation (Qualls and Shine, 1998; Goodwin et al., 2002).

The evolutionary history of elasmobranchs, particularly their reproductive modes, suggests the possibility that elasticity patterns may reflect phylogenetic constraints. The multivariate analysis suggested that at the superorder and order level, patterns in elasticity and demographics in elasmobranch species broadly conformed to phylogenetic relationships. At the family level, Rajidae species formed a group separate from other elasmobranchs and were clearly distinguishable from Carcharhinidae. These findings suggest that phylogeny, demographics and population dynamics are indeed linked. Thus, similar conservation efforts may be applied successfully to closely related species. 

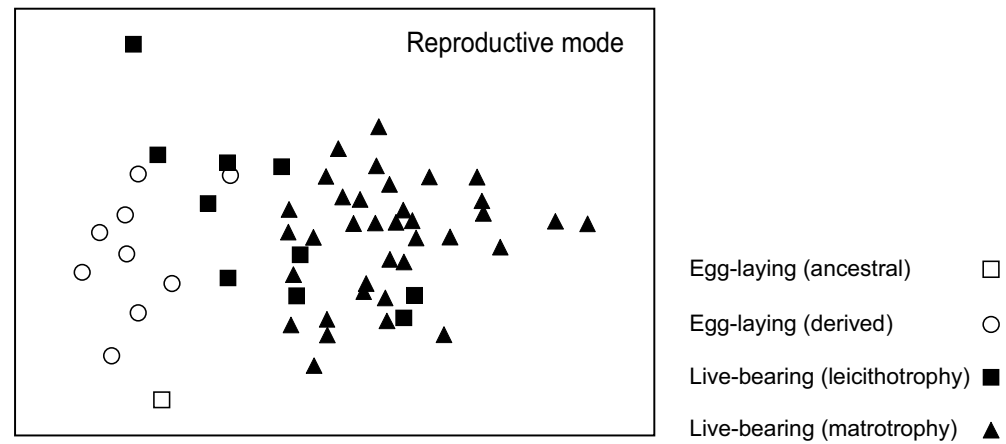

Fig. 13. MDS ordination of elasmobranch life histories and elasticities overlaid with the reproductive mode of each species. Reproductive mode follows Dulvy and Reynolds (1997).

A clear separation between Rajidae and the other elasmobranch families indicated a divide between egglayers and live-bearers, but may also indicate that skates are a particularly unusual group. Fecundity estimates were higher in Rajidae than in other elasmobranchs, while age at maturity and longevity were not significantly different (Average fecundity: Rajidae, $n=9$, mean $\left( \pm C L_{95 \%}\right)=27.2$ \pm 12.4 ; Other elasmobranchs, $n=47,5.4 \pm 2.36$ ). With further research, it may be possible to determine if energetic expenses in reproductive effort differ between egg-layers and live-bearers, both at the level of individual offspring and with regard to total investment. With this caveat, our results suggest that energy per offspring is smaller in egg-layers provided total annual reproductive investment is the same for both groups (Smith and Fretwell, 1974; Einum and Fleming, 2000). This suggests that egg-layers may invest less energy to ensure early juvenile survival and more in fecundity, i.e. utilize a bet-hedging strategy (Stearns, 1992). Yet, demography of only a few egg-laying species has been studied. Clearly data and models for egg-layers, from taxa other than the Rajidae, are required to answer these questions.

Elasticity is robust for the range of exploitation levels likely in elasmobranchs and using a "snapshot approach" (relatively fixed vital rates) should suffice in most management schemes unless extreme changes in survival are expected to occur in individual populations. While there were differences in the response to exploitation, elasticity of all species showed less than a $5 \%$ change in values with exploitation levels of fishing mortality $<1.0$. While elasticity provided a "snapshot" view, the sensitivity of elasticity allowed for a more flexible view of the impact of variation in vital rates. We calculated the sensitivity of elasticity for the stage that had the greatest elasticity of $\lambda$ in order to observe how that stage's elasticity is af- fected by perturbation of other stages. This goes beyond the simple observation of elasticity and instead views the consequences of the dynamics in vital rates. We showed both negative and positive effects of perturbing vital rates. However, the magnitudes of change and not the direction are of importance. For all species, the transition from the juvenile to the adult stage was high, indicating the importance of attaining maturity in elasmobranchs

Contributions of fertility to the stage with the greatest elasticity of $\lambda$ were low for all species. Long-lived species, often have low elasticity of $\lambda$ to changes in fertility, and the perturbation analyses further indicated that the dynamics of elasmobranchs are not strongly influenced by egg/neonate production. These findings are contrary to what intuitively might be expected, and other authors have suggested that matrix models provide unreasonable elasticity of $\lambda$ values for changes in fertility (Mollet and Cailliet, 2002). However, there is evidence to suggest there may be little scope or potential for varying fecundity. Firstly, demographic modeling suggests that further increases in egg production would have diminishing returns for three western Atlantic skates (Frisk et al., 2002). Secondly, body cavity limitation and energetic constraints may impose phenotypic canalization on fecundity in elasmobranchs (Brander, 1981). Therefore, we suggest that compensatory responses in changes in fecundity are not likely to occur. This is consistent with a recent age-based comparative analysis (Cortés, 2002). However, compensatory responses decreasing the age of maturity may increase lifetime egg production, while average fecundity remains constant. It appears that elasmobranch population dynamics are strongly influenced by juvenile and adult survival and the age of maturity but not fertility (Walker and Hislop, 1998; Heppell et al., 1999; Musick, 1999; Brewter-Geisz and Miller, 2000; Frisk et al., 2002). 
Recent research on population regulation has given supporting evidence that compensatory responses in fertility are not likely. Density-dependence in life histories has been suggested for the sharpose shark and spiny dogfish (Carlson and Baremore, 2004; Sosebee, 2004). In both cases, fecundity values were not density-dependent. Rather, the spiny dogfish showed a decrease in age of maturity and the sharpnose shark showed an increase in growth after a period of high exploitation (Carlson and Baremore, 2004; Sosebee, 2004).

Elasticity provides a convenient measure of life history trade-offs. Thus, trade-offs between vital rates (for example, reproduction $v s$ survival) may be reflected in the partitioning of elasticity. Elasticity also provides a measure of the intensity of selection pressure in each stage of a model (Caswell, 2001). We assumed that all species in this analysis can be represented with our three-stage model, which will, to some extent, produce similar patterns in elasticity. A similar approach to ours was successfully used for analyzing elasticity trends and trade-offs in plant species (Silvertown et al., 1993; Silvertown et al., 1994; but see Shea et al., 1994). Caswell (2001) pointed out that the assumption of one model structure representing all species introduces bias, and this limitation should be borne in mind. The central concern centers on annualizing trade-offs among related species using elasticity from a single model structure that may or may not capture the diversity of life histories of the species. However, we feel that trade-offs can be expressed in our analyses and that the life histories of elasmobranchs do not deviate sufficiently from the basic three-stage structure to apply similar criticisms of Shea et al. (1994) and Caswell (2001).

Our results provide a method of prioritizing stages of a species life history that will effectively respond to management options, particularly efforts to increase juvenile and adult survival that would have the greatest impact on population protection (see Cortés, 2002 for similar results using uncertainty in demographic models for 41 shark populations). We agree with Cortés (2002) and Heppell et al. (1999) that caution should be used when setting management policy with elasticity analysis alone, as they do not adequately show the impact on other life stages of targeting a certain stage. The method we used to calculate elasticities here and used by Cortés (2002) does not reflect density-dependent dynamics. However, our sensitivity of elasticity results does add some insight into potential interactions between life stages and potential stages for compensatory behavior.

\section{Acknowledgements}

We thank D. D. Davis $\left(D^{3}\right)$, M. J. Fogarty and R. E. Ulanowicz for constructive comments on earlier versions of this manuscript. Kyle Shertzer of the NMFS in Beaufort, $\mathrm{NC}$ provided help in estimating sensitivities of elasticity and general scientific advice. M.G. Frisk is thankful for support through the National Marine Fisheries Service Sea/Grant fellowship in population dynamics (Grant number NA17RG1375). N. K. Dulvy is grateful to Defra (MFD 0729) for funding his contribution to this research. This is contribution number 3779 of the University of Maryland Center for Environmental Science Series.

\section{References}

BENTON, T. G., and A. GRANT. 1999. Elasticity analysis as an important tool in evolutionary and population ecology. Trends in Ecology and Evolution, 14(12): 467-471.

BRANDER, K. 1981. Disappearance of the common skate Raja batis from the Irish Sea. Nature, 290: 48-49.

BREWSTER-GEISZ, K. K. and T. J. Miller. 2000. Management of the sandbar shark, Carcharhinus plumbeus: implications of a stage-based model. Fishery Bulletin 98(2): 236-249.

CASEY, J. M. and R. A. MYERS. 1998. Near extinction of a large widely distributed fish. Science, 281: 690-692.

CASWELL, H. 1996. Second derivatives of population growth rate: Calculation and applications. Ecology, 77(3): 870-879.

2001. Matrix population models: construction, analysis, and interpretation. $2^{\text {nd }}$ Edition, Sinauer Associates $722 \mathrm{p}$.

CHARNOV, E.L. 1993. Life History Invariants: Some Explorations of Symmetry in Evolutionary Ecology. Oxford University Press, Oxford. p. 167.

CLARKE, K. R. and R. M. WARWICK. 1994. Change in Marine Communities: An Approach to Statistical Analysis and Interpretation. Natural Environmental Research Council.

CLARKE, K. R. and R. N. GORLEY. 2001. PRIMER v5: User manual/tutorial. PRIMER-E, Plymouth, UK, 91 p.

CORTÉS, E. 1998. Demographic analysis as an aid in shark stock assessment and management. Fisheries Research 39(2): 199-208.

2002. Incorporating uncertainty into demographic modeling: application to shark populations and their conservation. Conservation Biology, 16(4): 1048-1062.

DE KROON, H., VAN J. GROENENDAEL and J. EHRLEN. 2000. Elasticities: a review of methods and model limitation. Ecology, 81(31): 607-618.

DENNEY, N.H., S. JENNINGS, and J. D. REYNOLDS. 2002. Life-history correlates of maximum population growth rates in marine fishes. Proceedings of the Royal Society of 
London, B 269(1506): 2229-2237

DULVY, N. K., J. D. METCALFE, J. GANVILLE, M. G. PAWSON, and J. D. REYNOLDS. 2000. Fishery stability, local extinctions, and shifts in community structure in skates. Conservation Biology, 14(1): 283-293.

DULVY, N. K. and J. D. REYNOLDS 1997. Evolutionary transitions among egg-laying, live-bearing and maternal inputs in sharks and rays. Proceedings of the Royal Society of London, B 264(1386): 1309-1315.

EINUM, S. and I. A. FLEMING. 2000. Highly fecund mothers sacrifice offspring survival to maximize fitness. Nature, 405(6786): 565-567.

FENCHEL, T. 1974. Intrinsic rate of natural increase: the relationship with body size. Oecologia, 14: 317-326.

FOGARTY, M. J., J. G. CASEY, N.E. KOHLER, J. S. IDOINE, and H. L. PRATT. 1987. Reproductive dynamics of elasmobranch populations in response to harvesting, ICES Mini-Symposium: reproductive variability. Paper No. 9, $21 \mathrm{p}$.

FRISK, M. G., T. J. MILLER, and M. J. FOGARTY. 2001. Estimation and analysis of biological parameters in elasmobranch fishes: A comparative life history study. Canadian Journal of Aquatic and Fisheries Science, 58(5): 969-981.

2002. The population dynamics of little skate Leucoraja erinacea, winter skate Leucoraja ocellata, and barndoor skate Dipturus laevis: predicting exploitation limits using matrix analyses. ICES Journal of Marine Science 59(3): 576-586.

GOODWIN, N. B. , N. K. DULVY, and J. D. REYNOLDS. 2002. Life history correlates of the evolution of live-bearing in fishes. Philosophical Transactions of the Royal Society of London, B 356: 259-267.

2002. Life-history correlates of the evolution of live bearing in fishes. Proceedings of the Royal Society of London, B 357(1419): 259-267.

HARVEY, P. H. and M. D. PAGEL. 1991. The Comparative Method in Evolutionary Biology. Oxford University Press, Oxford, $239 \mathrm{p}$.

HEPPELL, S.S., L. B. CROWDER, T. R. MENZEL, and J. A. MUSICK. 1999. Life table analysis of long-lived marine species with implications for conservation and management, In: Life in the Slow Lane: Ecology and Conservation of Long-Lived Marine Animals., J. A. Musick (ed.). American Fisheries Society Symposium, 23: 137-146.

HEPPELL, S.S., H. CASWELL, and L. B. CROWDER. 2000. Life histories and elasticity patterns: pertabation analysis for species with minimal demographic data. Ecology, 81: 654-665.

HOENIG, J. M. 1983. Empirical use of longevity data to estimate mortality rates. Fishery Bulletin 81(4): 898-903.

JENNINGS, S, J. D. REYNOLDS, and S. C. MILLS. 1998. Life history correlates of responses to fisheries exploitation. Proceedings of the Royal Society of London, B 265(1393): 333-339.

MOLlET, H. F. and G.M. CAILLIET. 2002. Comparative population demography of elasmobranchs using life history tables, Leslie matrices and stage-based matrix models. Marine and Freshwater Research, 53(2): 503-516.

MUSICK, J.A. 1999. Ecology and conservation of long-lived marine animals, In: Life in the Slow Lane: Ecology and Conservation of Long-Lived Marine Animals. J. A. Musick (ed.) American Fisheries Society Symposium, 23: 1-7.

PAGEL, M. D. and P. H. HARVEY. 1988. Recent development in the analysis of comparative data. Quarterly Review of Biology, 63: 413-440.

QUALLS, C. P., and R. SHINE. 1998. Lerista bougainvillii, a case study for the evolution of viviparity in reptiles. Journal of Evolutionary Biology, 11(1): 63-78.

REYNOLDS, J. D., S. JENNINGS, and N.K. DULVY. 2001. Life histories of fishes and population responses to exploitation, In: Conservation of Exploited Species. J. D. Reynolds, G. M. Mace, K. H. Redford and J. G. Robinson (eds.) Cambridge University Press, Cambridge, 147-168.

ROFF, D. R. 2002. Life History Evolution. Sinauer Associates, Sunderland, Massachusetts p. 527.

SHEA, K., M. REES, and S.N. WOOD. 1994. Trade-offs, elasticities and the comparative method. Journal of Ecology, 82(4): 951-957.

SILVERTOWN, J., M. FRANCO, I. PISANTY, and A. MENDOZA. 1993. Comparative plant demography - relative importance of life-cycle components to the finite rate of increase in woody and herbaceous perennials. Journal of Ecology, 81(3): 465-476.

SILVERTOWN, J., A. FITTER, and J. VANGROENENDAEL. 1994. Journal of Ecology, 82(1): 1-1.

SIMPFENDORFER, C. A. 2000. Predicting population recovery rates for endangered western Atlantic sawfishes using demographic analysis. Environmental Biology of Fishes, 58(4): 371-377.

SMITH, S. E., D.W. AU, and C. SHOW. 1998. Intrinsic rebound potentials of 26 species of Pacific sharks. Marine and Freshwater Research, 49(7): 663-678.

SMITH, C. C. and S. D. FRETWELL. 1974. Optimal balance between size and number of offspring. American Naturalist, 108(962): 499-506.

STEARNS, S. C. 1992. The Evolution of Life Histories. Oxford University Press, New York, 249 p.

STEVENS J. D., R. BONFIL, N. K. DULVY and P. A. WALKER. 2000. The effects of fishing on sharks, rays, and chimaeras (chondrichthyans), and the implications for marine ecosystems. ICES Journal of Marine Science, 57(3): 476-494.

WALKER, P. A., and J. R. G HISLOP. 1998. Sensitive skates or resilient rays? Spatial and temporal shifts in ray species composition in the central and north-western North Sea between 1930 and the present day. ICES Journal of Marine Science, 55(3): 392-402.

WOURMS, J. P. 1977. Reproduction and development in chondrichthyan fishes. American Zoologist, 17(2): 379-410.

WOURMS, J. P. and J. LOMBARDI. 1992. Reflections on the evolution of piscine viviparity. American Zoologist, 32(2): 276-293. 
